\title{
Effect of Knee Joint Angle on a Heteronymous Ib Reflex in the Human Lower Limb
}

\author{
J.D. Brooke and W.E. McIlroy
}

\begin{abstract}
Altered efficacy, from change in receptor discharge with different positions of the knee, was investigated in a heteronymous Ib reflex of the human leg. The electrical stimulus was low threshold, to the common peroneal nerve. The divergence of the group I afferents was studied in the electromyograms (EMGs) of ipsilateral and contralateral thigh muscles. The stimulus evoked ipsilateral, short latency, excitation in the three quadriceps muscles studied and inhibition in the knee flexor semitendinosus (ST), with prior contraction of target muscles. This excitation and inhibition did not alter when studied over the range of the knee joint. The stimulus did not evoke responses in contralateral thigh muscles, contracted or relaxed. It is concluded that (1) any change in convergence from discharge of receptors, during extension of the limb, is small and sub-threshold, and (2) this spinal proprioceptive level of neural control appears to be directed primarily to the single limb.
\end{abstract}

RÉSUMÉ: Effet de l'angle articulaire du genou sur un réflexe Ib hétéronyme du membre inférieur chez l'homme Nous avons investigué la modification de l'efficacité d'un réflexe Ib hétéronyme de la jambe chez l'humain à partir de changements dans la décharge des récepteurs selon la position du genou. Le stimulus électrique administré au nerf péronier commun était de faible intensité. La divergence des afférents du groupe I a été étudiée dans les électromyogrammes des muscles de la cuisse ipsilatérale et contralatérale. Le stimulus évoquait une excitation ipsilatérale de courte latence dans les trois muscles quadriceps étudiés et une inhibition dans le muscle fléchisseur demi-tendineux du genou, avec contraction préalable des muscles cible. Cette excitation et cette inhibition n'étaient pas modifiées quand l'étude portait sur toute l'étendue de l'articulation du genou. Le stimulus n'évoquait pas de répose dans les muscles de la cuisse contralatérale, qu'ils aient été contractés ou relachés. Nous concluons que 1) tout changement dans la convergence de la décharge des récepteurs pendant l'extension du membre est petit et sous le seuil et que 2) ce niveau de contrôle neural spinal proprioceptif semble être dirigé primordialement à un seul membre.

Can. J. Neurol. Sci. 1989; 16: 58-62

We have recently investigated a group Ib oligosynaptic spinal reflex which links afferent activity from the pretibial flexor muscles of the ankle to excitation of vastus medialis (VM). ${ }^{1}$ The pathway appears to be specific to the human, ${ }^{2}$ and may prepare the limb for heel strike in gait. ${ }^{3}$

Mao et $\mathrm{al}^{3}$ concluded that the reflex was $\mathrm{Ib}$ mediated, in a study of reflex excitation of single motor units. They reported that its threshold of $0.85 \mathrm{MT}$ (where MT is the threshold to evoke an $M$ wave in tibialis anterior, from direct activation of alpha motoneurons) was significantly higher than the $0.79 \mathrm{MT}$ required for Ia reflex effects from the common peroneal nerve. Pierrot-Deseilligny et $\mathrm{al}^{2}$ also concluded that the pathway was served by Ib fibres, on the basis of $0.7 \mathrm{~ms}$ increase in latency and 0.03 increase in MT, compared to the Ia reflex. We have observed that 20 minutes of vibration of the TA muscle, suffi- cient to substantially depress the Ia $(H)$ short latency reflex in TA, does not alter the magnitude of the reflex in VM. ${ }^{4}$ The presently reported mean reflex latency of $24.5 \mathrm{~ms}$ overestimates the true reflex latency, due to averaging. At that latency, and assuming an alpha motoneuronal conduction velocity of 57 $\mathrm{m} / \mathrm{sec}$ with a disynaptic path, the average limb lengths of the subjects results in a conduction velocity for the afferent arm of $59.0 \mathrm{~m} / \mathrm{sec}$. In contrast, the rapidly conducting cutaneous fibres of the human lower limb are reported to lie in the range of 45.2 $-49.1 \mathrm{~m} / \mathrm{sec}^{5}$ On these various experimental grounds, the afferents of this heteronymous pathway are indirectly classified as group Ib. The reflex is spinal, and probably is oligosegmental. ${ }^{6}$

The considerable convergence onto the interneurons in such Ib pathways ${ }^{7}$ can alter reflex expression. For example, voluntary contraction of VM is necessary, if the excitation is to be

From the Neurophysiology Laboratory, Biophysics Interdepartmental Group and School of Human Biology, College of Biological Science, University of Guelph, Guelph

Received March 29, 1988. Accepted in final form August 23, 1988

Reprint requests to: J.D. Brooke, Neurophysiology Laboratory, College of Biological Science, University of Guelph, Guelph, Ontario, Canada N1G 2W I 
expressed as muscle action potentials. ${ }^{1}$ The present paper investigated three other aspects of the spinal circuitry involved in this short latency system linking the segments of the human lower limb. Firstly, the convergence from differential discharge of receptors, as the knee joint altered, was studied. This particularly has the potential to alter muscle mechanoreceptor and joint receptor discharge. [The current view appears to be that the joint receptors discharge across the range of joint excursion in cats $\left.^{8}\right]$. Secondly, divergence of the activated afferents to reciprocal inhibitory action in the thigh muscles was identified. Moreover, both facilitatory and inhibitory potentials in human hamstring motoneurons, after stimulation of group I fibres in the common peroneal nerve have been reported. ${ }^{2}$ Presently, the effect of the Ib stimulus was observed in the ST muscle. Thirdly, any divergence to contralateral projections, that would have the potential to reset the gait pattern, was also explored. Contralateral projections have been described for group I fibres in the cat. ${ }^{9}$ [The present work has been partly reported in abstract. $\left.{ }^{10}\right]$

\section{MeTHOD}

The six subjects were of mean height $171 \mathrm{~cm}$, standard deviation (SD) $8 \mathrm{~cm}$, weight $63 \mathrm{~kg}$, SD 9 and age 26 years, SD 11 . No subjects reported histories of neuromuscular or metabolic diseases and all were informed volunteers. The experimental protocol was approved by the University ethics committee.

Pairs of $\mathrm{Ag}-\mathrm{AgCl}$ recording electrodes were placed $20 \mathrm{~mm}$ apart on the skin, longitudinally to the muscle fibres over the tibialis anterior (TA), VM, vastus lateralis, rectus femoris, and ST muscles, to record EMG potentials. Stimulating electrodes were placed on the skin at caput fibula, running longitudinal to the common peroneal nerve, with the anode distal. ${ }^{1}$

The signals from the EMG electrodes were amplified 2000 times with a band pass filter from $3 \mathrm{~Hz}$ to $3 \mathrm{kHz}$ (Grass $\mathrm{P} 511$ amplifiers) and visually inspected on a digital storage oscilloscope. The biopotentials were digitized at a rate of 1000 samples per second through an A/D interface (Tecmar Labmaster) and stored on a microcomputer (modified PC, IBM), to a precision of $\pm 5 \mathrm{uV}$. The $1 \mathrm{~ms}$ square wave pulse of stimulating current was delivered through a Grass S88 stimulator and stimulus isolation unit (Grass SIU5). The impedance of the stimulating and recording electrodes was $<5 \mathrm{kohms}$, measured with test pulses at $30 \mathrm{~Hz}$ (Grass EZM5 impedance meter). The stimulus current was standardized to 1.6 times MT, measured for each joint position. This intensity was chosen to evoke maximum amplitudes of the VM reflex.

Recordings of EMGs were made over $100 \mathrm{~ms}$ sampling periods. The nerve was stimulated after the first $30 \mathrm{~ms}$. The latencies and peak to peak amplitudes of the reflexes observed in the EMGs were calculated from averages of 20 to 50 samples per subject. The level of prior contraction in the muscle was measured from the average of full wave rectified EMGs in the first $30 \mathrm{~ms}$ of collection. Both the level of prior contraction and the reflex magnitude were standardized to the maximum EMG potentials (full wave rectified and raw, respectively) that occurred in the largest of three maximum voluntary contractions (MVC), each sampled for one second at the appropriate position of the knee joint.

During data collection, subjects sat in a rigid-framed chair. Measurements were made with the knee joint at extensions of $60^{\circ}, 110^{\circ}$ and $175^{\circ}$. The hip joint remained constant at $75^{\circ}$ flexion and the ankle was in a relaxed position with the foot free of support. For the concentric contractions, at an angular velocity of approximately $75 \% \mathrm{sec}$ at the knee joint, the stimuli were delivered as the joint passed the appropriate angles. The subjects were requested to maintain the EMG constant at target lines, on an oscilloscope, constituting 20 to $30 \%$ MVC. The order of presentation of knee position to subjects, for EMG measurements in ipsilateral VM was by randomized Latin square, with pseudorandom sampling for ipsilateral ST, vastus lateralis and rectus femoris and contralateral VM and ST.

\section{RESULTS}

The results of stimulating the common peroneal nerve, in homonymous and heteronymous muscle, are illustrated in Figure 1. In Part A, M waves and small $\mathrm{H}$ reflexes can be seen in the EMGs of TA. The short latency response in VM is shown at 'SL' in Part C of Figure 1. The latency of the reflex, measured from the average trace, was $24.5 \mathrm{~ms}$, duration $14.2 \mathrm{~ms}$. The stimulus artifact is shown by ' $S$ ', on the traces of $V M$ and TA. For this subject, the VM muscle was contracted on average at $20.7 \%$ MVC, SD $4.8 \%$. It can be seen that, in comparison to the differences within a trial, only small differences occurred in the mean reflex magnitudes when they were evoked with the knee at the three different degrees of extension.

The responses from isometric contractions in the VM muscles of three subjects are reported in Part E of Figure 1. Between the three positions of the knee, there was no significant difference in the mean amplitude of the VM reflex. [By analysis of variance, $F(2,4)=2.1 \mathrm{p}>0.05$.] The EMG activity in the MVC was higher at $60^{\circ}$, although not significantly so, and this may be the basis for the non-significant reduction in reflex amplitude at that position. Thus no effect was observed from any differential convergence from receptor discharge with the knee joint at the different positions. The stimulus evoked a comparatively constant $M$ wave and there was no significant difference in the mean level of tonic contraction in VM, or in the reflex latency and duration, over the three knee positions.

With VM contracted concentrically the results for one subject are shown in Figure 1D. These reflex amplitudes show some increase as the knee extends, especially in the early part. In another subject, the reverse trend occurred. These appear to be random variations and the mean results from the three subjects are very similar over the three positions of the joint, as shown in Figure 1F. As in the first experiment, none of the mean statistics were significantly different over the three knee positions [For reflex amplitude, $\mathrm{E}(2,4)=0.5, \mathrm{p}<.05$ ]

The Ib afferents also excited two other quadriceps muscles, vastus lateralis and rectus femoris, in the two subjects studied, with similar amplitudes to those in VM. Recordings were made at all three of the positions of the knee joint in one of the subjects but, as in VM, the reflex amplitudes of vastus lateralis and rectus femoris did not differ systematically across positions. The latencies and durations complemented those obtained in VM.

There was a brief spinal route for the stimulated afferents to the posterior thigh muscle, ST, where the reflex was expressed in three subjects as inhibition, at a latency similar to the excitation of VM. Figure 1B illustrates inhibition in a trial of 50 
samples from one subject, with ST isometrically contracted. The latency was $33.9 \mathrm{~ms}$ from the average trace. The latency for VM excitation in that subject was also $33.9 \mathrm{~ms}$. The duration of the inhibition was $9.5 \mathrm{~ms}$. The inhibition occurred in six out of nine trials (three of six subjects tested) with the muscle contracted, constituting 180 samples over all. The durations were all less than $17 \mathrm{~ms}$. There was no differentiation of the reflex inhibition due to knee joint position, or due to type of contraction. In fifteen other trials, the relaxed ST muscle was observed following the stimulus, and, as with contraction, no reflex excitation was seen.

Divergence to contralateral vastus medialis was examined in five trials with the muscle contracted and seventeen with it relaxed, at all three knee joint positions. No reflex excitation or inhibition was observed, up to $60 \mathrm{~ms}$ post-stimulus. This was also the case for the contralateral ST muscle, where four trials were made with the muscle tonically contracted and twelve with it relaxed.

\section{Discussion}

It is reported that the receptors of limb joints alter their discharge as a function of the position of the joint and that discharge can be observed over the full range of the joint. ${ }^{8}$ The discharge from muscle spindle and Golgi tendon organs could also alter as the position of the knee was altered. It is clear, from the present results on averages drawn from a total of 1120 samples of the Ib heteronymous reflex, that the convergence from the sum of such discharge, ${ }^{11}$ does not change sufficiently to alter the amplitude of reflex muscle action potentials evoked in the thigh muscles, following low threshold stimulation of the common peroneal nerve. No systematic change was observed in the Ib reflex responses of the quadriceps group, or in the limited sample of reflex inhibition in the ST muscle. The convergence from joints can be sufficiently powerful to be expressed in muscle action potentials in cat gait. ${ }^{12}$ As the present reflex EMGs were unchanged by joint position, the strength of convergence
A

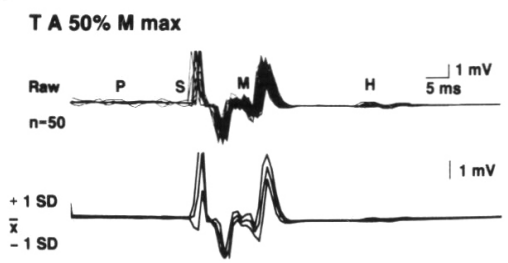

C

VM Isometric Contractions

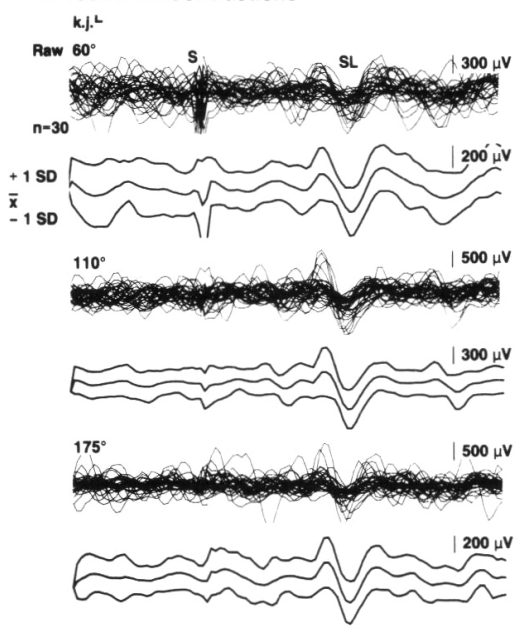

E Means and SDs, 3 Subjects, Isometric C.

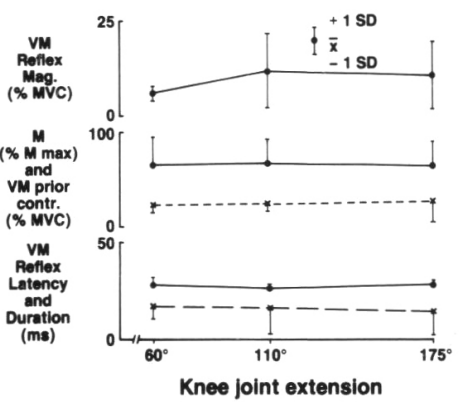

B

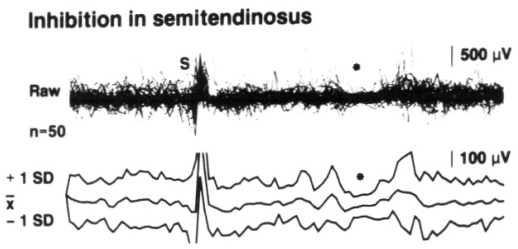

D

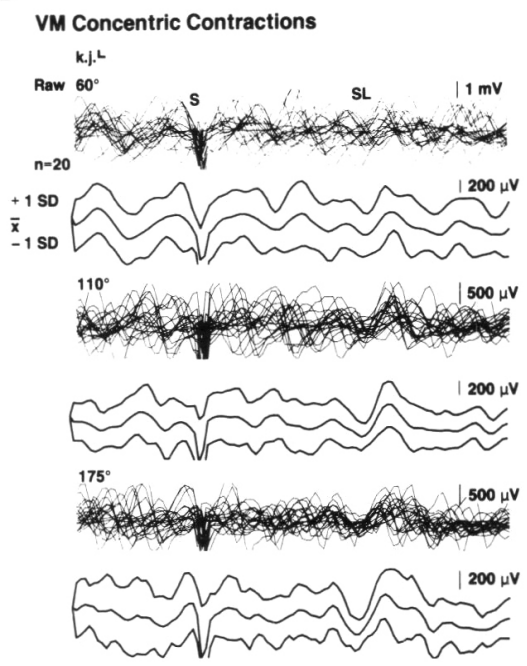

F Means and SDs, 3 Subjects, Concentric C.

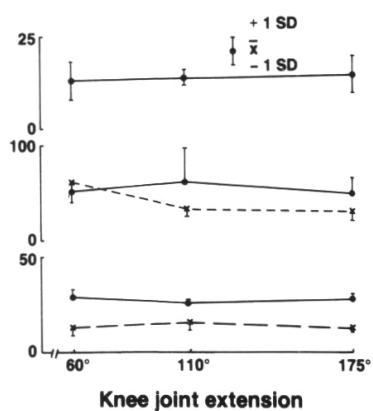

Figure 1 - Reflex EMGs from stimulation (S) of the common peroneal nerve. A. Direct motoneuronal $(M)$ and spinal $(H)$ homonymous responses in tibialis anterior (TA), after $30 \mathrm{~ms}$ pre-stimulus interval $(P)$. B. Reflex inhibition $\left(^{*}\right)$ in semitendinosus. C, D. Short latency (SL) reflex EMGs in vastus medialis (VM) at three angular positions of the knee joint (k.j.) with isometric and concentric contractions respectively in one subject. $E, F$. Statistics for the responses in $C$, and $D$, from three subjects. 
of this receptor discharge may be similar across the range of motion of the human knee joint.

Lemon and Porter ${ }^{13}$ observed that the most powerful peripheral input to motor cortex in the unanaesthetized monkey comes from joint movement. Currently, there was no differential reflex effect from the receptors associated with knee joint movement (during the concentric contractions of VM). This indicates that any modulation of this input, from one comfortable extreme of the joint to the other, at the spinal level in the human was modest, compared to the convergence from the stimulated Ib afferents or compared to that for voluntary contraction.

The amplitudes of Group I reflexes are strongly modulated in humans during stepping, ${ }^{14}$ pedalling, ${ }^{15}$ walking and running. ${ }^{16}$ During pedalling, the amplitude of the present reflex in VM systematically varied from a peak average value of $36 \%$ MVC to zero, dependent upon where in the pedal cycle the reflex was evoked. ${ }^{15}$ Similar systematic variation is seen for the $H$ reflex in soleus during running, with values in the region of $4.0 \mathrm{mV}$ peak to peak, during the stance phase, completely disappearing during the period when the leg swings. ${ }^{16}$ The present results show that changing the knee position, held in isometric contraction, does not much alter the efficacy of the Ib reflex. When the knee joint opens from concentric contraction of quadriceps, the reflex is not changed. This suggests that the knee position itself may not be a primary determinant of the modulation of this group Ib reflex during movement. The matter needs experimental investigation, as the segmental interneuronal pathway will be different during locomotion, compared to the present episodic contractions of muscles. The variation seen in group I reflex magnitude, during movement, has been attributed to both pre-synaptic and post-synaptic mechanisms. ${ }^{1}$ 5,16

The inhibition evoked in ST likely arose from post synaptic inhibitory potentials, rather than pre-synaptic inhibition, as the latter is more long lasting than the present brief duration $(<17$ $\mathrm{ms}$ ). The latency of this ST inhibition was within $0.4 \mathrm{~ms}$ of the VM reflex latency in the same subjects. The similarity suggests that the inhibitory effect is mediated through group I fibres, as the fast acting cutaneous fibres have slightly slower conduction velocities from the lower leg and foot in humans, as discussed earlier. ${ }^{5}$ This inhibition in the posterior thigh presently is associated with Ib fibres, as it is reciprocal to the Ib excitation in the anterior thigh. Also, the inhibition of ST motoneurons reported by Pierrot-Deseilligny et $\mathrm{al}^{2}$ was classified as $\mathrm{Ib}$, on the basis of its latency compared to Ia effects.

The present Ib excitation to quadriceps may support the synergy between the pre-tibial flexors and VM, seen at heel strike in human gait. ${ }^{3}$ Reciprocal reflex relaxation of hamstring muscles at that point would remove a potential impediment to such coordination of the limb.

It was of interest that no contralateral divergence of the reflex could be identified. In the decerebrate cat, stimulation of Ib afferents in the tibial nerve results in activation of contralateral flexor and extensor muscles of the ankle. ${ }^{17}$ Others proposed that the source of action is through neurons intercalated in the ipsilateral pathways. ${ }^{9}$ However, they noted that contralateral post-synaptic potentials with group I activation only occurred occasionally, and were weak. The present results suggest that any group I contralateral interaction likely will be too slight for a resetting of human gait. Such resetting has been seen with discharge from group III fibres. ${ }^{14}$

At the segmental level, the neural control from the present afferents appears substantially to be restricted to the movement of the single, ipsilateral, limb. Control of the single limb appears in a diversity of experimental approaches. For example, little "timing cross-talk" was seen, when subjects pedalled an ergometer on which the pedals gradually lost synchrony. ${ }^{18}$ The timing of EMG bursts for the propulsive phase of the single limb were little affected by the out of phase activity of the other leg. There appeared to be little contralateral intrusion into the control. Also, a recent multivariate principal components analysis of the sources of variation in the main reaction force when pedalling, concluded that the two main orthogonal components represented control of the two limbs individually. ${ }^{19}$ Such a theme, of the limb as a control unit, also emerges from investigations of the central generation of locomotor patterns. 20 Clearly, for natural behaviours such as gait in intact humans, these units of control must be drawn into a wider control system involving the whole body and the goal of the task.

\section{ACKNOWLEDGEMENTS}

This work was partially supported by grant \#A0025 from the Natural Sciences and Engineering Research Council of Canada and a grant from the Banting Research Foundation.

\section{REFERENCES}

1. McIlroy WE, Brooke JD. Human group I excitatory projections from ankle dorsiflexors to quadriceps muscle. Can J Physiol Pharmacol 1987; 65: 12-17.

2. Pierrot-Deseilligny E, Morin C, Bergego C, et al. Pattern of group 1 fibre projections from ankle flexor and extensor muscles in man. Exp Brain Res 1981; 42: 337-350.

3. Mao CC, Ashby P, Wang M, et al. Synaptic connections from large muscle afferents to the motoneurons of various leg muscles in man. Exp Brain Res 1984; 56: 341-350.

4. Brooke JD, McIlroy WE, Wright D. Characterization of the human heteronymous projection from pre-tibial ankle flexors to excite the thigh muscle, vastus medialis. Proc XXXth Cong Intl Union Physiol Sci IUPS Vancouver, 1986; 256.

5. Burke D, Gandevia SC, McKeon B. The afferent volleys responsible for spinal proprioceptive reflexes in man. J Physiol 1983; 339: 535-552.

6. Sharrard WJW 1964. In: Warwick R, Williams PL (eds); Gray's Anatomy, 35th Ed Longmans London UK 1973; 815.

7. Binder MD. Introduction: Changing perspectives on the functional organization of the segmental motor system. Can J Physiol Pharmacol 1986; 64: 495-498.

8. Ferrell WR. The adequacy of stretch receptors in the cat knee joint for signalling joint angle throughout a full range of movement. J Physiol 1980; 299: 85-99.

9. Harrison P, Zytnicki D. Crossed actions of group I muscle afferents in the cat. J Physiol 1984; 356: 263-273.

10. Brooke JD. Ipsilateral and contralateral study of heteronymous and homonymous group I reflexes in the human lower limb extended over the range of the knee joint. Neuroscience 1987; 22: S826.

11. Baldissera $F$, Hultborn $H$, Illert $M$. Integration in spinal systems. In: Brooks VB (ed). Handbook of Physiology, sect 1 vol 2 Motor Control, Am Physiol Soc Baltimore MD 1981; 509-595.

12. Ferrell WR, Baxendale RH, Carnachan $\mathrm{C}$, et al. The influence of joint afferent discharge on locomotion, proprioception and activity in conscious cats. Brain Res 1985; 347: 41-48.

13. Lemon RN, Porter R. Afferent input to movement-related precentral neurones in conscious monkeys. Proc Roy Soc B 1976; 194 313-339. 
14. Crenna P, Frigo C. Excitability of the soleus H-reflex arc during walking and stepping in man. Exp Brain Res 1987; 66: 49-61.

15. Brooke JD, Mcllroy WE. Movement modulation of a human Ib initiated heteronymous reflex. Neurosci Abs 1987; 13: 1426.

16. Capaday C, Stein RB. Difference in the amplitude of the human soleus H-reflex during walking and running. J Physiol 1987; 392: 513-522.

17. Baxendale RH, Rosenberg JR. Crossed reflexes evoked by selective activation of tendon organ afferent axons in the decerebrate cat. Brain Res 1976; 127: 323-326.
18. Boylls CC, Zomlefer MR, Zajac FE. Kinematic and EMG reactions to imposed interlimb phase alterations during bipedal cycling. Brain Res 1984; 342: 342-345.

19. Hines WGS, O'Hara-Hines RJ, Brooke JD. A multivariate solution for cyclic data, applied in modelling locomotor forces. Biol Cybern 1987; 56: 1-9.

20. Grillner S. Control of locomotion in bipeds, tetrapods and fish. $\ln$ : Brooks VB (ed). Handbook of Physiology, sect 1 vol 2 Motor Control, Am Physiol Soc Baltimore MD 1981; 1179-1236. 